\title{
Predicting voluntary turnover in employees using demographic characteristics: A South African case study
}

\begin{abstract}
Authors:
Anton F. Schlechter

Chantal Syce ${ }^{1}$

Mark Bussin ${ }^{2}$

Affiliations:

${ }^{1}$ School of Management

Studies, University of Cape

Town, South Africa

${ }^{2}$ Department of Industrial Psychology and People

Management, University of

Johannesburg, South Africa

Corresponding author and

email:

Anton Schlechter

anton.schlechter@uct.ac.za

Dates:

Received: 03 June 2014

Accepted: 23 Mar. 2015

Published: 09 Mar. 2016

How to cite this article:

Schlechter, A.F., Syce,

C. \& Bussin, M., 2016

'Predicting voluntary

turnover in employees using

demographic characteristics:

a South African case study',

Acta Commercii 16(1), Art.

\#274, 10 pages. http://dx.do

org/10.4102/ac.v16i1.274

\section{Copyright:}

C 2016. The Authors. Licensee: AOSIS. This work

is licensed under the

Creative Commons

Attribution License.
\end{abstract}

Purpose: Employee turnover presents arguably the biggest threat to business sustainability and is a dynamic challenge faced by businesses globally. In South Africa, organisations compete to attract and retain skilled employees in an environment characterised by a burgeoning skills deficit. Turnover risk management is becoming an important strategy to ensure organisational stability and promote the effective retention of employees. The purpose of this research was to contribute to the practice of turnover risk management by proposing an approach and constructing a model to predict employee turnover based on demographic characteristics readily available in a human resource information system.

Design: An exploratory research design was employed. Secondary quantitative data were extracted from an existing human resources database and analysed. Data obtained for 2592 employees in a general insurance company based in South Africa and Namibia formed the basis for the analysis. Logistic regression analysis was employed to predict employee turnover using various demographic characteristics available within the database. A likelihood ratio test was used to build a predictive model and the Akaike information criterion and Schwarz criterion were used to test how much value each variable added to the model and if its inclusion was warranted. The model was tested by conducting statistical tests of the significance of the coefficients. Deviance and Pearson goodness-of-fit statistics as well as the $R$-square test of significance were used. The overall goodness-of-fit of the model was also tested using the Hosmer and Lemeshow goodness-of-fit test.

Findings: The current findings provide partial support for a predictive model explaining employee turnover. The model tested 14 demographic variables and the following five variables were found to have statistically significant predictive value: age, years of service, cost centre, performance score and the interaction between number of dependants and years of service. It is proposed that these five demographic variables be used as a model to help identify employees at risk of turnover or termed as flight risks.

Practical implications: Gaining an understanding of the factors that influence employee voluntary turnover can be instrumental in sustaining workforce stability. The proposed model could help human resources professionals identify employees at risk of turnover using data that are readily available to them. This will further enable the use of targeted interventions to prevent turnover before it happens. Decreased levels of turnover will result in cost saving, enhanced talent management and greater competitive advantage.

\section{Introduction and literature review}

The purpose of this research was to propose an approach to construct a model that could predict employee turnover based on demographic characteristics or variables readily available in most organisations' staff databases.

\section{Context}

Employee turnover presents a significant threat to business sustainability and is a dynamic challenge faced by businesses globally. Despite the economic downturn, turnover remains one of the most relevant and significant issues in human resource management (Robison 2010; Vance, Vaiman \& Andersen 2009). The consequences of turnover are likely to be particularly severe in cases where experience is a critical prerequisite for successful work, where replacement is expensive and where turnover is disruptive and demoralising to the remaining workforce (Allen, Bryant \& Vardaman 2010).

There are significant costs associated with turnover that include direct recruitment costs incurred whilst searching for a replacement, lost productivity on the part of the departing employee, lost labour between the time the individual quits and a replacement is hired and reduced productivity 
of the new hire whilst learning the job (Cascio \& Boudreau 2008). Organisations often make a significant investment in training and developing their employees and this investment is also lost when employees leave (Mello, 2011). Estimates of the overall cost of turnover range from $90 \%$ to $200 \%$ of the departing employee's salary (Cascio \& Boudreau 2008).

Other consequences of turnover include a reduction in customer satisfaction, loss of organisational knowledge and ultimately reduced profit (Harter, Schmidt \& Keyes 2003). Excessive employee turnover can hurt the overall productivity of a firm and is often a symptom of other difficulties (Iqbal 2010).

In South Africa the demand for skilled employees has continued to increase due to an ageing population and growth in the local economy (Journal of E-Governance 2010). Organisations are forced to compete to attract and retain skilled employees in an environment characterised by a burgeoning skills deficit. The impact of affirmative action and employment equity legislation exacerbates the turnover problem. The retention of skilled employees has thus become a strategic imperative which is critical to business success.

Various explanations have been postulated to explain the growing skills deficit in South Africa, such as rapid economic growth and an increasing need for infrastructure, buildings and electricity. The changing age demographics within the country also play a role. As more baby boomers (born 1946-1964) start retiring, the quantity and quality of available skills becomes a greater problem (Rappaport, Bancroft \& Okum 2003).

The Global Competitiveness Report 2011-2012 ranks South Africa 50th in the ranking of competitiveness out of 59 nations, indicating a decline from the previous year. The International Institute for Management Development (IMD) generated the rankings using 331 criteria ranging from gross domestic product growth and unemployment, to the number of Internet users and the price of local cell phone calls. Other criteria included the availability of skilled employees, government regulation, availability of venture capital and various qualitative factors. The IMD report shows that a critical component of competitiveness includes having the appropriate skills quota across a range of occupations and professions as well as the skills to drive leadership in organisations (Journal of E-Governance 2010).

Consequently, in their retention strategies, organisations use both targeted and untargeted approaches in managing employee turnover. Untargeted approaches rely on generic organisational practices to increase organisational commitment and retain employees (Westerman \& Yamamura 2007). These approaches include increasing compensation and benefits, promotions, opportunities to learn, special assignments and status-driven incentives. Other untargeted non-monetary retention strategies include increased flexibility and work-at-home options, flexible control over work schedules and additional opportunities to develop skills and knowledge during work time or through employer-funded educational programmes (Westerman \& Yamamura 2007).

Targeted approaches rely on identifying employees who are likely to leave and then providing them with either a direct incentive or a customised plan to ensure that they stay. Effective retention strategies hinge on reliable, timely intelligence about prospective leavers (Lyness \& Judiesch 2001; Trevor, Gerhart \& Boudreau 1997).

Targeted and untargeted retention approaches aimed at managing voluntary turnover form part of turnover risk management and are becoming an increasingly important strategy to ensure organisational stability, sustainability and success.

\section{Voluntary turnover}

Recruitment, development and retention of talent form the basis for developing competitive advantage in many industries and countries (Pfeffer 2005). In addition, whilst voluntary turnover may appear to be easily predicted by macro-economic data, decades of research propose that a rich understanding of individual behaviour under constantly evolving global and local conditions will necessitate continuous research efforts.

Employee turnover is a well-researched concept with published literature focusing on its causes dating back to the mid-1900s. Whilst several researchers have observed that work and non-work characteristics influence employee turnover, associated research has concentrated predominantly on work-related variables (for example, Baek-Kyoo \& Sunyoung 2010; Carraher 2011; Chen et al. 2011; Mobley 1982; Mosadeghrad, Ferlie \& Rosenberg 2008; Mowday, Porter \& Steers 1982). Previously, researchers were directed by embedded paradigms (Mobley 1982) and despite progress in turnover research, concerns have been raised that the degree of incremental knowledge generated by these studies is limited (O'Reilly, Chatman \& Caldwell 1991). According to Somers and Birnbaum (1999), perspectives on employee turnover have changed. As a possible response to these opinions, new approaches to studying employee turnover are evident in recent turnover research.

There has been an increase in studies investigating individual variables that relate to turnover such as the role of the psychological contract (Clinton \& Guest 2014), the cognitive ability of employees (Maltarich, Nyberg \& Reilly 2010) and even moral stress (DeTienne et al. 2012). There have also been new studies linking turnover to individuals engaging in ongoing cycles of job search to remain employable in a volatile economy (Direnzo \& Greenhaus 2011).

\section{Determinants of employee turnover}

Variables that generally predict employee turnover have been summarised in three meta-analytic studies (Cotton \& Tuttle 
1986; Griffeth, Hom \& Gaertner 2000; Tett \& Meyer 1993). The most recent of these (Griffeth et al. 2000) categorised the predictors as:

1. Employee demographics.

2. Current job conditions.

3. Organisation and the external environment.

Demographic characteristics have been advanced in several models as predictors of turnover (Bal et al. 2011; Deumert 2010), but few studies have examined the demographicturnover correlation in isolation. Other organisational variables, such as job satisfaction, frequently tend to form part of the studies.

Turnover literature has been led by research on how work attitudes (for example commitment and job satisfaction) influence turnover (Mossholder, Setton \& Henagan 2005). Whilst this contribution to the literature has been significant, it has been at the expense of studying less traditional turnover variables, such as demographic variables.

Wocke and Heymann (2012) investigated the role of demographic variables as extended factors in the voluntary turnover process in South Africa. Their findings indicate that various demographic variables (for example age, race and gender) influence whether pull or push factors are cited in the turnover process. They also found that level of education has a stronger relationship with employee mobility than race. Based on their results they asserted that employee demographic variables should be considered in the extension of contemporary turnover models.

Vandenberg and Nelson (1999) indicate that identifying predictive precursor variables to turnover is important for the understanding and management thereof. This illustrates the need to develop a predictive model to tackle the problem of employee turnover.

\section{Problem statement}

Employee turnover is an important research topic in the fields of organisational behaviour, human resources management and labour economics. Consequently, there is an increasing need to understand the major variables affecting turnover. Such understanding will hopefully lead to the advancement of turnover risk management, which is becoming an important strategy to ensure organisational stability and promote the effective retention of employees.

The relationship between demographic variables and voluntary turnover is a topic of interest for a number of researchers. Although a cursory examination of the literature suggests that consensus exists regarding the nature of this relationship, a more detailed analysis reveals significant disagreement. This lack of consensus leads to different conclusions and limits theoretical development within this research space.
The purpose of this research was to contribute to the practice of turnover risk management by proposing an approach and constructing a model that is able to predict employee turnover solely based on demographic characteristics readily available in a typical human resource information system. It is believed that organisations can use such an approach to model predictors of turnover without having to collect primary data and so efficiently identify employees that are potential flight risks. Once these employees are identified, decisions can be made as to whether and to what extent retention measures need to be put in place to try and retain such employees.

\section{Research design and objectives Research objectives}

The primary objective of this research was to create a model that could be used to predict employee turnover by using demographic variables readily available to organisations. It was important in this study to make use of data that are already available in organisations, rather than consider variables for which data specifically needs to be collected. This would essentially be a stand-alone model for determining the probability of whether an employee will stay with or leave an organisation. The research also aimed to provoke greater thinking and reflection on the measurement of employee turnover.

The researchers hypothesised that demographic variables could be used to build a statistically significant model to predict and identify employees at risk of turnover.

\section{Research design}

An exploratory research design was employed. Secondary data weres extracted from an existing human resources database at a general insurance organisation and analysed.

\section{Population}

A large insurance organisation, headquartered in Cape Town, South Africa, was selected to serve as a case study. The organisation has approximately 60 branches throughout South Africa and Namibia. The study utilised secondary data collected on employees who were permanently employed with the organisation as of 2008 and who had voluntarily left the organisation between 2008 and 2011. This group represented the sample. Employees who had left the organisation on an involuntary basis were excluded from the study. A total of 2592 employees were included in the sample.

\section{Data collection and analysis}

The data were collected from the organisation's human resources information system. Company records included an observation of the database of the years 2008-2011. The organisation provided 22 data fields for each individual employee record, of which only 14 variables were selected 
for analysis. The input data contained the demographic characteristics of each employee. The dependent variable was an indicator of whether the employee had voluntarily terminated their employment. Each employee was assigned an identification number and entered into a data file. The SAS program was used to conduct the statistical analysis.

Exploratory data analysis was conducted in order to summarise the relationships of the independent variables and eliminate those that did not relate to voluntary employee turnover.

\section{Model and variable selection}

The technique of data mining, a branch of applied informatics, was utilised for this study. Two high-level goals of data mining were identified: description and prediction (Wang et al. 2011). All data was cleaned, screened and coded before statistical analysis was performed.

Various models were considered and the best one was selected based on predictive performance (i.e. explaining the variability in question and producing stable results across samples). Forward stepwise regression was used to select variables that could significantly predict variance. The forward selection technique begins with no variables in the model. Demographic variables are subsequently added to the model one at a time. At each step, any variable that is not already in the model is tested for inclusion in the model. The most significant of these variables is added to the model, as long as its $p$-value is below the pre-set level. The Akaike information criterion (AIC) and Schwartz criterion (SC) were also used to test how much value a variable added to a model and if its inclusion was warranted.

\section{Ethics and confidentiality}

It would have been impossible to gain consent from all participants in the study; therefore, the custodian of organisation employee data (the Head of Human Resources), was approached and permission requested to gain access to the data.

Permission to conduct this research was granted with the following confidentiality provisions:

1. The name of the organisation would not be indicated, only the industry.

2. Only two people were granted access to the raw data (i.e. the researcher and the internal statistical associate).

3. The data would not be given to parties outside the organisation.

4. Access to the HR information system was given for a specified period of time and terminated thereafter.

5. The organisation would have veto rights over whether the research could be published.

6. Some employee information was not made available for the research (i.e. current salary and salary increases).

The Commerce Ethics in Research Committee at UCT further granted ethical permission to conduct this study.

\section{Research limitations}

This study considered only limited variables when assessing employee turnover. Critical variables, for example, qualification and salary were excluded. This exclusion was deliberate as the research aimed to isolate the impact of demographic variables to validate their value in predicting turnover. The sample was also limited to one general insurance organisation. It may not be appropriate to generalise the findings across other populations or settings; however, the sample can be viewed as a representative case typical of many other organisations in the same industry.

\section{Results \\ Descriptive statistics}

Table 1 shows the distribution of the sample $(n=2592)$ by current age, gender, race, language and marital status.

From Table 1, it can be seen that the majority of the employees ( $n=871$ or $34 \%$ ) were in the age group $40-50$ years, whilst $31 \%(n=785)$ were in the age group $40-50$ years. The numbers indicated a mature workforce with the under-30s representing $15 \%$ of the sample.

The majority of employees were white people (52\%). The ratio of white people to black people (mixed race, Indian and black people combined) employees was 52:48; in an organisation where transformation is one of the strategic drivers, the issue of retention of non-white employees in a highly skilled industry with notable skills scarcity is critical to organisational success.

Afrikaans (52\%) and English (36\%) were the most common languages used by employees. Most of the sample was

TABLE 1: Demographic characteristics of the sample $(N=2592)$.

\begin{tabular}{|c|c|c|c|}
\hline Variable & Value & Count: Frequency & $\begin{array}{l}\text { Frequency } \\
\%\end{array}$ \\
\hline \multirow[t]{2}{*}{ Gender } & Male & 1097 & 42.3 \\
\hline & Female & 1495 & 57.7 \\
\hline \multirow[t]{4}{*}{ Race } & White & 1348 & 52.0 \\
\hline & Mixed race & 648 & 25.0 \\
\hline & Black & 409 & 15.8 \\
\hline & Indian & 187 & 7.2 \\
\hline \multirow[t]{5}{*}{ Age band } & $20-30$ & 386 & 14.9 \\
\hline & $31-40$ & 871 & 33.6 \\
\hline & $41-50$ & 785 & 30.3 \\
\hline & $51-60$ & 480 & 18.5 \\
\hline & $60+$ & 70 & 2.7 \\
\hline \multirow[t]{4}{*}{ Language } & Afrikaans & 1348 & 52.0 \\
\hline & English & 922 & 35.6 \\
\hline & Damara† & 1 & 0.0 \\
\hline & $\begin{array}{l}\text { Other African } \\
\text { language }\end{array}$ & 313 & 12.1 \\
\hline \multirow[t]{5}{*}{ Marital status } & Married & 1481 & 57.1 \\
\hline & Single & 821 & 31.7 \\
\hline & Divorced & 223 & 8.6 \\
\hline & Common law & 18 & 0.7 \\
\hline & Widowed & 48 & 1.9 \\
\hline
\end{tabular}

$\dagger$, A language spoken in Namibia. 
married (57\%) with a very small number of employees being divorced $(9 \%)$ or widowed $(2 \%)$.

\section{Model selection}

Since turnover is a dichotomous variable, a logistic regression model was used in this study (Quinn, Rycraft \& Schoech 2002). The forward selection technique began with no variables in the model. Explanatory variables were subsequently added to the model one at a time. At each step, each variable that was not already in the model was tested for inclusion. The likelihood ratio test was used to test if adding a variable was of significant value. The $p$-values of the test were quoted. Automated model building software packages could not be used because some variables were collinear. Collinear variables, which are not eligible for inclusion in the model, have crosses in place of their statistics. The most significant of these variables were added to the model.

The AIC and SC were used to test how much value a variable added to the model and if its inclusion was warranted. The results of these tests are illustrated in Table 2 and Table 3 respectively.

Step 1 of the model selection process showed that the cost centre band was clearly the most powerful variable. The corresponding small $p$-value and AIC were much smaller than those calculated for the other variables.

TABLE 2: Variable selection with Akaike information criterion.

\begin{tabular}{lcc}
\hline Variable & \multicolumn{2}{c}{ Step 1 } \\
\cline { 2 - 3 } & $\boldsymbol{P}$-value & AIC \\
\hline$\sim$ & $<0.0001$ & 1571 \\
Occupation level & 0.2235 & 1573 \\
Job grade & 0.2202 & 1573 \\
Performance score & 0.0070 & 1565 \\
Years' service & 0.0002 & 1557 \\
Race & 0.0347 & 1568 \\
Province & 0.0008 & 1553 \\
Age band & 0.0002 & 1544 \\
Marital status & 0.0055 & 1565 \\
Business unit & 0.1057 & 1569 \\
Cost centre band & $<0.0001$ & 1285 \\
Number of dependants & 0.1134 & 1570 \\
\hline
\end{tabular}

$\sim$ Null model (models the response without any covariates included).

AIC, Akaike information criterion.

TABLE 3: Variable selection with Schwarz criterion.

\begin{tabular}{lccccc}
\hline Variable & \multicolumn{2}{c}{ Step 2 } & & \multicolumn{2}{c}{ Step 3 } \\
\cline { 2 - 3 } \cline { 5 - 6 } & $\boldsymbol{P}$-value & SC & & $P$-value & SC \\
\hline Occupational level & - & 1330 & & - & 1321 \\
Job grade & 0.1521 & 1365 & & 0.4332 & 1356 \\
Performance score & 0.9712 & 1331 & & 0.4304 & 1322 \\
Years' service & 0.0323 & 1324 & & 0.0592 & 1316 \\
Race & 0.0091 & 3121 & & - & - \\
Province & 0.6579 & 1342 & & 0.6537 & 1333 \\
Age band & 0.9297 & 1381 & & 0.9656 & 1373 \\
Marital status & 0.0070 & 1340 & & - & - \\
Number of dependants & 0.0874 & 1339 & & 0.3281 & 1333 \\
\hline
\end{tabular}

$\sim$ Null model.

SC, Schwarz criterion.
In step 2, the business unit variable could not be fitted to the model because cost-centre had already been included and the two are collinear. This iteration process showed that the number of years of service was the most powerful variable despite the fact that it had the second lowest $p$-value. The SC calculated for the inclusion of years of service was the smallest and so warranted the inclusion of this variable rather than that of age.

In step 3, the age variable could not be fitted to the model because years of service had already been included and the two are highly correlated. This iteration process showed that the performance score variable was the most powerful variable. The corresponding small $p$-value and SC were much smaller than those calculated for the other variables.

In step 4, the inclusion of an interaction term was tested (refer to Table 4).

Whilst several variable interactions were tested, the most powerful turned out to be the interaction between the number of dependants and the years of service with a $p$-value of 0.087 and SC of 1310.

\section{Testing the statistical significance}

Tests of the statistical significance of each independent variable were conducted. The Wald chi-square test (and its associated $p$-value) are shown along with the parameter estimate and standardised parameter estimate in Table 5.

To test the prediction, the chi-square test statistic for the predictor performance score was 3.59 with an associated $p$-value of 0.0581 . If the alpha level had been set to 0.05 , it would have failed to reject the null hypothesis and concluded that the difference in performance has not been found to be statistically different for employees who leave and those who stay.

\section{Odds ratio estimates}

Next, the effect size of the relationship was estimated by using odds ratio. The odds ratio gives the increase or decrease in probability that a unit change in the independent variable has in the probability that the event of interest will occur. It shows the strength of association between a predictor (independent variable) and the dependent variable. Breaugh (2003) indicates that it could vary from 0 to infinity and, if the odds ratio is 1 , there is no relationship.

\section{Cost centre bands}

Due to the sheer number of cost centres or departments in the organisation, the individual cost centres were placed into

TABLE 4: Variable interaction Schwarz criterion.

\begin{tabular}{lcc}
\hline Variable & \multicolumn{2}{c}{ Step 4 } \\
\cline { 2 - 3 } & $\boldsymbol{P}$-value & SC \\
\hline $\begin{array}{l}\text { Number of dependants } \\
\text { *Years' service }\end{array}$ & 0.087 & 1310 \\
\hline SC, Schwarz criterion. & & \\
\hline
\end{tabular}

SC, Schwarz criterion 
TABLE 5: Analysis of maximum likelihood estimates.

\begin{tabular}{|c|c|c|c|c|c|c|}
\hline Parameter & Level & Estimate & Standard error & Odds ratio & Wald: Chi-squared & $P$-value \\
\hline Intercept & - & -3.7218 & 1.0457 & - & 12.6672 & 0.0004 \\
\hline cc_band & 1 & 2.9122 & 0.6711 & 18.39723 & 18.8281 & $<0.0001$ \\
\hline cc_band & 2 & 3.4924 & 0.6553 & 32.86473 & 28.4045 & $<0.0001$ \\
\hline cc_band & 3 & 3.6854 & 0.6947 & 39.86106 & 28.1472 & $<0.0001$ \\
\hline cc_band & 4 & 4.1085 & 0.6443 & 60.85537 & 40.658 & $<0.0001$ \\
\hline cc_band & 5 & 4.2905 & 0.6686 & 73.00296 & 41.1778 & $<0.0001$ \\
\hline cc_band & 6 & 4.3267 & 0.6495 & 75.69408 & 44.3747 & $<0.0001$ \\
\hline cc_band & 7 & 5.3962 & 0.6558 & 220.5667 & 67.7162 & $<0.0001$ \\
\hline Performance score & - & -0.0151 & 0.00798 & 0.985013 & 3.5905 & 0.0581 \\
\hline Years'_service & - & -0.0229 & 0.0106 & 0.97736 & 4.6601 & 0.0309 \\
\hline Years'_service*kids & 1 & 0.0176 & 0.016 & 1.017756 & 1.1978 & 0.2738 \\
\hline Years'_service*kids & 2 & -0.0127 & 0.0175 & 0.98738 & 0.5284 & 0.4673 \\
\hline Years' service*kids & 3 & -0.012 & 0.0418 & 0.988072 & 0.0818 & 0.7748 \\
\hline
\end{tabular}

TABLE 6: Odds estimate ratio.

\begin{tabular}{lc}
\hline Effect & Point estimate \\
\hline cc_band 1 vs 0 & 18.397 \\
cc_band 2 vs 0 & 32.864 \\
cc_band 3 vs 0 & 39.863 \\
cc_band 4 vs 0 & 60.857 \\
cc_band 5 vs 0 & 73.002 \\
cc_band 6 vs 0 & 75.694 \\
cc_band 7 vs 0 & 220.561 \\
Performance score & 0.985 \\
Years'_service & 0.977360215 \\
Years' service*kids 1 & 1.017755793 \\
Years' service*kids 2 & 0.987380305 \\
Years' service*kids 3 & 0.988071713 \\
\hline
\end{tabular}

homogenous bands (see Table 6). These bands were used to classify cost centres with the lowest and highest turnover on a scale of 0 (lowest) to 7 (highest). Table 6 indicates association between the predictor and the explanatory variables identified for inclusion in the model.

In the model building process, the cost centre variable was the most powerful and there was a large difference in turnover between the cost centre bands (as indicated in Table 3). For example, an employee whose cost centre fell in CC Band 7 was 220 times more likely to leave the organisation than an employee in Band 0. Not only was this effect large, but it was highly significant ( $p$-value $<0.001$, Table 2$)$.

\section{Performance score}

Table 3 indicates that for every one-point increase in performance score, the likelihood of turnover deceased by $2 \%(1-0.98=0.02=2 \%)$. This effect was also significant with a $p$-value of 0.0581 .

\section{Years of service}

Table 3 indicates that for every year of service the likelihood of turnover decreased by 3\% $(1-0.97=0.03=3 \%)$. This effect also seemed to be very significant with a $p$-value of 0.0309 . The interaction between years of service (continuous variable) and the number of dependants (categorical variable) was complex and warranted a detailed discussion to understand its effect. To this end, simultaneous regression was used.
TABLE 7: Effect of number of children on years of service.

\begin{tabular}{lcc}
\hline Number of children & Final coefficient for years of service & Odds ratio \\
\hline 0 & -0.0229 & 0.97736 \\
1 & -0.0053 & 0.994714 \\
2 & -0.0356 & 0.965026 \\
$\geq 3$ & -0.0349 & 0.965702 \\
\hline
\end{tabular}

\section{Simultaneous regression}

The logistic regression models were computed using simultaneous regression to identify the strongest predictors of turnover with other potential predictors held constant. The results appear in Table 7.

Table 7 shows the effect of the number of children variable when it is allowed to change and years of service is held constant. When the employee has no children, the odds of leaving are $2.26 \%(1-0.97736=2.264 \%)$ less likely for each successive year of service. If the employee has one child, then these odds change with each successive year of service, only making the odds of leaving $0.53 \%$ $(1-0.994714=0.005286)$ less likely. Similarly, the odds of leaving are $3.5 \%(1-0.965026=3.4974 \%)$ and $3.42 \%$ $(1-0.965702=3.4298 \%)$ less for each successive year of service when an employee has two and three or more children respectively.

\section{Model testing}

After estimating the coefficients there were several steps involved in assessing the appropriateness, adequacy and usefulness of the model. The importance of each of the explanatory variables was assessed by carrying out statistical tests of the significance of the coefficients. The overall goodness-of-fit of the model was tested. Then the ability of the model to discriminate between the two groups defined by the response variable was evaluated.

In Figure 1 actual resignations are shown on the right (yellow bar) and predicted resignations are shown on the left (blue bar). Aside from testing the model graphically to test predictability, goodness-of-fit tests were performed. All of these confirmed the fact that the model does fit the turnover data well. 


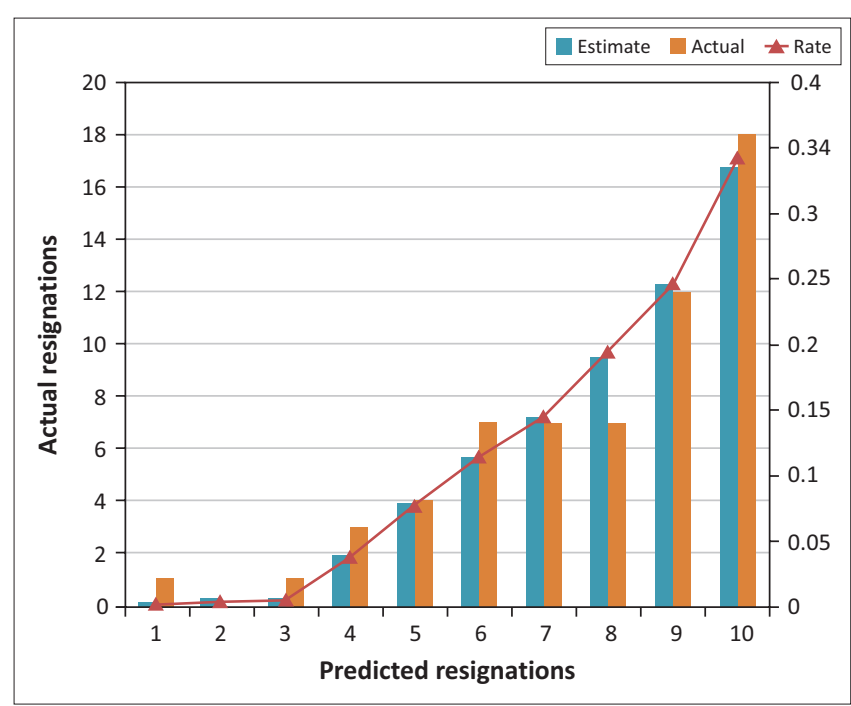

FIGURE 1: Comparison of actual and predicted resignations using the test set.

TABLE 8: Hosmer and Lemeshow goodness-of-fit test.

\begin{tabular}{lcc}
\hline Chi-squared & DF & Pr $>$ Chi-squared \\
\hline 5.889 & 8 & 0.6597 \\
\hline
\end{tabular}

TABLE 9: Deviance and Pearson goodness-of-fit statistics.

\begin{tabular}{lcccc}
\hline Criterion & Value & DF & Value/DF & Pr $>$ Chi-squared \\
\hline Deviance & 1277.3333 & 2060 & 0.6201 & 1 \\
Pearson & 1915.4071 & 2060 & 0.9298 & 0.9892 \\
\hline
\end{tabular}

TABLE 10: $R$-squared test of significance.

\begin{tabular}{lc}
\hline $\boldsymbol{R}$-squared & Max-rescaled $\boldsymbol{R}$-squared \\
\hline 0.1332 & 0.2591 \\
\hline
\end{tabular}

\section{Test results}

The results of the tests can be found in Tables 8,9 and 10 below.

The pseudo $R$-squared for the model was low but the other tests (Table 8 and Table 9) seem to indicate that this was a result of its shortcomings in the context of logistic regression.

\section{Discussion of results}

In the present study, logistic regression analysis was employed to predict the probability that an employee would voluntarily leave the organisation. The model tested 14 demographic variables; the following five variables were found to have statistically significant predictive value and hence were included in the model:

1. Age.

2. Years of service.

3. Cost centre.

4. Performance score.

5. Interaction (number of dependants and years of service).

Each one of the five variables is discussed in greater depth, followed by a brief discussion of the excluded variables.

\section{Age}

The literature supports the finding that age influences employee decisions to leave an organisation. For example, mature workers are less likely than younger ones to intend to leave an organisation. Younger employees have higher turnover rates as a result of shifting career paths, flexibility to relocate and fewer family responsibilities and financial obligations (Lewis 1991). Generational differences also encourage younger employees to change jobs and sector of employment frequently after earning their degrees (Peralta \& Stark 2006). As Generations X and Y place less value on stability and benefits, there is a greater likelihood of turnover amongst these groups (Lewis \& Frank 2002).

In the current logistic regression study, no assumptions were made about the distributions of the explanatory variables. The explanatory variables should not be highly correlated with one another because this could cause problems with estimations. The age variable could not be fitted to the model because years of service was already included and the two are most likely highly correlated. The differences in turnover attributable to age were clear. Employees younger than 35 years had higher turnover rates than their older colleagues, with the propensity to leave actually increasing with age amongst the younger employees. The main argument for this observation was that the available time to amortise the costs related to a change in employment declines with age, thus making a job change more risky (Sousa-Poza \& Henneberger 2004).

\section{Years of service}

According to traditional research, years of service has consistently been found to be negatively related to turnover (Griffeth et al. 2000; Steel \& Ovalle 1984; Steers 1977). In this study the highest turnover was experienced in the first four years of employment. New employees take time to adjust to their work environment. At the same time, they are still evaluating whether their decision to join the organisation was the right career choice. In addition, in the first few years of employment, new employees would not have financially invested in the organisation. Their pension fund and other benefits would not have accrued to the point that leaving the organisation would disadvantage them financially. Therefore, job mobility becomes easier.

The research confirmed that after every year of service, voluntary turnover decreases. A $p$-value of 0.0309 meant years of services was included in the model. Whilst age and years of service are positively correlated, they are not identical constructs (Ng \& Feldman 2009). Nonetheless, older workers with high years of service may have particularly strong financial reasons to remain with their current employers. Good compensation benefits are offered to employees with long years of service in order to retain them. $\mathrm{Ng}$ and Feldman (2009) suggest that these rewards discourage employees from seeking alternative opportunities. Whilst older workers are less likely to leave their organisations in general, those 
with long years of service are especially less likely to do so because of financial incentives.

Job tenure (referred to as years of service) also seems to have a strong negative influence on turnover (Blau \& Kahn 1981; Cotton \& Tuttle 1986; Lambert, Hogan \& Barton 2001; Lewis 1991; Sorenson 2000). Turnover is greatest at the earliest stages of employment, but it declines rapidly over the first 5 years and then more slowly up to about 15 years of service (Lewis 1991). A principal explanation for this trend is that social interaction in the workplace tends to engender affinity and loyalty toward the organisation and its members, thus reducing the propensity for turnover (Sorenson 2000). As an employee remains with an organisation over time, they will be motivated to respond to changes within it by exiting, voicing concern or remaining loyal. Once an employee has a certain number of years of experience in employment, they may refrain from leaving or retiring early out of consideration for the potential loss in retirement earnings.

\section{Cost centre}

Cost centre refers to an organisation unit in which all costs related to a group of people are managed. It could be a specific department but also within a department, a few cost centres may exist. Bands were used to classify cost centres with the lowest and highest turnover on a scale of 0 (lowest) to 7 (highest). The inclusion of cost centre in the model was unexpected but not unexplained. Table 11 shows which business unit contributes most to a particular (turnover) band.

As broker distribution has the largest number of cost centres, it will almost always be the largest contributor to turnover due to the size of the business unit $(N=1066)$. Table 11 also shows that within business units (e.g. business change), there is very little likelihood of turnover. Table 11 indicates that there is not much turnover in all its cost centres falling into bands 1 and 2. Broker distribution, claims services and specialist business appear to have cost centres that have high turnover. Within these business units, there are specific cost centres that have a higher predictive turnover probability than other cost centres (e.g. band 7).
These cost centres are based in Gauteng. Possible explanations could include all of the traditional turnover factors, including leadership, job satisfaction and commitment, worker engagement, employee benefits and the nature of the work. This study suggests that people working in Gauteng are more susceptible to turnover than people living anywhere else, but it is suggested that this assertion needs to be tested in future research. This could be explained by the fact that Johannesburg offers greater access to alternative career opportunities as large South African and international offices are based there.

\section{Performance score}

The findings suggest that voluntary turnover can be predicted based on performance $(p$-value $=0.0581)$. The performance-turnover relationship (i.e. positive, negative or no relationship) is supported by the literature. The literature advises that the performance-turnover relationship should consider performance slopes when predicting turnover (Sturman \& Trevor 2001). Alternatively, other researchers suggest that the performance-turnover relationship may be of greater importance in the intermediate stages of employment (Kanfer, Crosby \& Brandt 1988). In the current research, turnover was highest within the first four years of employment, which makes this a crucial period in retention.

The findings of this study strongly support the existence of a positive relationship between performance and turnover: the higher the level of performance, the lower the likelihood of turnover. The performance-turnover relationship indicates that the variable is useful in the final model but that its effect is likely to be marginal.

\section{Interaction of number of dependants and years of service}

The last component of the model is the relationship between years of service and number of dependants. In order to test for moderating effects, this study adopted a regression procedure. The method is that both categorical (e.g. years of service) and continuous (e.g. organisational years of service) moderator variables can be included. Employees who have same number of years of service and differences

TABLE 11: Cost centre band and turnover.

\begin{tabular}{|c|c|c|c|c|c|c|c|c|c|}
\hline \multirow[t]{2}{*}{ Business unit } & \multicolumn{8}{|c|}{ Cost centre band } & \multirow[t]{2}{*}{ Total } \\
\hline & 0 & 1 & 2 & 3 & 4 & 5 & 6 & 7 & \\
\hline Broker distribution & 97 & 6 & 4 & 2 & 7 & 8 & 15 & 15 & 154 \\
\hline Business change unit & 9 & 0 & 0 & 1 & 0 & 0 & 0 & 0 & 10 \\
\hline Claims services & 46 & 7 & 4 & 5 & 8 & 3 & 7 & 9 & 89 \\
\hline Corporate services & 15 & 0 & 2 & 1 & 1 & 2 & 2 & 2 & 25 \\
\hline Executive office & 2 & 0 & 0 & 0 & 0 & 0 & 0 & 1 & 3 \\
\hline Information technology & 9 & 1 & 1 & 0 & 3 & 0 & 0 & 1 & 15 \\
\hline Market development & 1 & 0 & 0 & 0 & 0 & 0 & 0 & 2 & 3 \\
\hline People and brand & 6 & 0 & 2 & 1 & 0 & 0 & 2 & 4 & 15 \\
\hline Risk services & 12 & 2 & 1 & 2 & 2 & 1 & 2 & 1 & 23 \\
\hline Special projects & 1 & 0 & 0 & 0 & 0 & 0 & 0 & 0 & 1 \\
\hline Specialist business & 13 & 1 & 1 & 1 & 4 & 1 & 1 & 6 & 28 \\
\hline Total & 211 & 17 & 15 & 13 & 25 & 15 & 29 & 41 & 366 \\
\hline
\end{tabular}


in the number of dependants show an equal likelihood of turnover.

\section{Critical evaluation of the model}

The research results support the use of a model for predicting voluntary turnover using demographic characteristics. The fact that only a few variables were included in the model raises significant questions, which are listed below with possible explanations.

\section{Why does the model not support the literature more strongly?}

In the data exploration phase of the study, there was clear support for the relationship between demographic variables and turnover. However, in the predictive model, there was less support for the demographic variable-turnover relationship.

\section{Exclusion of variables}

The study did not consider several variables that have been identified in the management and labour economics literature to be important determinants of turnover. These include wages, wage growth, education status and prior mobility (Ledolter \& Power 1984). Of these, wages and wage growth are probably most important for actuarial applications.

\section{One-dimensional model}

A primary limitation of this research was that the model was one-dimensional. It was developed using only data available internally within an organisation. The data did not directly capture influences from the macro and market environments that might have had an impact on employee turnover. Neither did the research focus on any of the traditional turnover models.

\section{Conclusion}

The current study attempted to predict employee turnover by developing a mathematical-based understanding of employee turnover. The model can hopefully guide the organisation when deciding which workforce segments should be approached in retention campaigns and implementation of segment-specific retention strategies. Through predicting turnover propensity, the organisation is likely to manage its human capital risks (Boudreau 2010).

The findings provide partial support for the predictive model in explaining employee turnover. Five out of the 14 predicted relationships were significant: age, years of service, cost centre, performance score and interaction (number of dependants and years of service).

Information on turnover can assist with the planning, prediction and control of resources (Shamsuzzoha \& Shumon 2007). This model can thus be used as an additional data point in being able to better understand and manage turnover in organisations. The specific focus on demographic characteristics portrayed in this research was deliberate from a research methodology perspective. In order to evaluate whether demographic characteristics can be used to predict voluntary turnover, it was necessary to exclude other individual and workplace variables. In practice, it is the combination of all of these variables and the use of multiple data points that provides the richness and diversity required to understand and predict complex phenomena like turnover. This research has demonstrated that certain demographic characteristics have a definite role to play in understanding and predicting voluntary turnover.

\section{Areas for future research}

Other demographical data and test results may be considered to improve the accuracy of the prediction or generate other potentially useful rules for this model. Further research is suggested to apply this basic model to a greater number of organisations in similar industries. However, in this application, the following should be considered:

- Analysis using survival analysis techniques, or duration analysis, could enable more precise prediction.

- Inclusion of external data would add a further dimension to turnover prediction (e.g. data related to economic conditions or job market conditions).

- Inclusion of salary information data would add value to the overall effectiveness of the model (Cho \& Ngai 2003; Doran et al. 1991).

Alternative data mining techniques such as neural networks could be studied in future research to compare various approaches and these techniques may be integrated for better exploration of complex interrelationships amongst the input personnel variables and target work behaviours (Sexton et al. 2005).

\section{Acknowledgements}

Shravan Lalbahadur for assistance with the statistical analysis.

\section{Competing interests}

The authors declare that they have no financial or personal relationship(s) that may have inappropriately influenced them in writing this article.

\section{Authors' contributions}

A.S. (University of Cape Town) was the project leader and academic supervisor and was responsible for the design of the project. C.S. (University of Cape Town) was responsible for field work and writing up the research. M.B. (University of Johannesburg) contributed to the preparation of the manuscript.

\section{References}

Allen, D.G., Bryant, P.C. \& Vardaman, J.M., 2010, 'Retaining talent: Replacing misconceptions with evidence-based strategies', Academy of Management Perspectives 24(2), 48-64. http://dx.doi.org/10.5465/AMP.2010.51827775 
Baek-Kyoo, J. \& Sunyoung, P., 2010, 'Career satisfaction, organizational commitment, and turnover intention: The effects of goal orientation, organizational learning culture and developmental feedback', Leadership \& Organization Development culture and developmental feedback', Leadership \& Organization Develor

Bal, P.M., De Lange, A.H., Ybema, J.F., Jansen, P.G.W. \& Van der Velde, M.E.G., 2011, 'Age and trust as moderators in the relation between procedural justice and turnover: A large-scale longitudinal study', Applied Psychology 60(1), 66-86. http://dx.doi.org/10.1111/j.1464-0597.2010.00427.x

Blau, F.D. \& Kahn, L.M., 1981, 'Causes and consequences of layoffs', Economic Inquiry 19(2), 270-296. http://dx.doi.org/10.1111/j.1465-7295.1981.tb01134.x

Boudreau, J.W., 2010, Retooling HR: Using proven business tools to make better decisions about talent, Harvard Business School Press, Boston, MA

Breaugh, J.A., 2003, 'Effect size estimation: Factors to consider and mistakes to avoid', Journal of Management 29(1), 79-97. http://dx.doi.org/10.1177/ 014920630302900106

Carraher, S.M., 2011, 'Turnover prediction using attitudes towards benefits, pay, and pay satisfaction among employees and entrepreneurs in Estonia, Latvia, and Lithuania', Baltic Journal of Management 6(1), 25-52. http://dx.doi.org/10.1108/ 17465261111100905

Cascio, W. \& Boudreau, J.W. 2008, Investing in people: Financial impact of human resource initiatives, Prentice-Hall, Upper Saddle River, NJ.

Chen, G., Ployhart, R.E., Thomas, H.C., Anderson, N. \& Bliese, P.D., 2011, 'The power of momentum: A new model of dynamic relationships between job satisfaction change and turnover intentions', Academy of Management Journal 54(1), change and turnover intentions', Academy of Managen
159-181. http://dx.doi.org/10.5465/AMJ.2011.59215089

Cho, V. \& Ngai, E.W.T., 2003, 'Data mining for selection of insurance sales agents', Expert Systems: International Journal of Knowledge Engineering and Neural Networks 20(3), 123-132. http://dx.doi.org/10.1111/1468-0394.00235

Clinton, M.E. \& Guest, D.E., 2014, 'Psychological contract breach and voluntary turnover: Testing a multiple mediation model', Journal of Occupational an Organizational Psychology 87, 200-207. http://dx.doi.org/10.1111/joop.12033

Cotton, J.L. \& Tuttle, J.M., 1986, 'Employee turnover: A meta-analysis and review with implications for research', Academy of Management Review 11(1), 55-70.

DeTienne, K.B., Agle, B.R., Phillips, J.C. \& Ingerson, M.C., 2012, 'The impact of mora stress compared to other stressors on employee fatigue, job satisfaction, and turnover: An empirical investigation', Journal of Business Ethics 110(3), 377-391. $\mathrm{http}: / / \mathrm{dx}$.doi.org/10.1007/s10551-011-1197-y

Direnzo, M.S. \& Greenhaus, J.H., 2011, Job search and voluntary turnover in boundaryless world: A control theory perspective', Academy of Management Review 36(3), 567-589. http://dx.doi.org/10.5465/AMR.2011.61031812

Doran, L.I., Stone, V.K., Brief, A.P. \& George, J.M., 1991, 'Behavioral intentions as predictors of job attitudes: The role of economic choice', Journal of Applied Psychology 76(1), 40-45. http://dx.doi.org/10.1037/0021-9010.76.1.40

Deumert, A., 2010, 'Tracking the demographics of (urban) language shift - An analysis of South African census data', Journal of Multilingual \& Multicultural Development 31(1), 13-35. http://dx.doi.org/10.1080/01434630903215125

Griffeth, R.W., Hom, P.W. \& Gaertner, S., 2000, 'A meta-analysis of antecedents and correlates of employee turnover: Update, moderator tests, and research implications for the next millennium', Journal of Management 26(3), 463-488. $\mathrm{http}: / / d x$.doi.org/10.1177/014920630002600305

Harter, J.K., Schmidt, F.L. \& Keyes, C.L.M., 2003, 'Well-being in the workplace and its relationship to business outcomes: A review of the Gallup studies', in C.L.M Keyes \& J. Haidt (eds.), Flourishing: Positive psychology and the life well-lived, pp. 205-224, American Psychological Association, Washington, DC. http://dx.doi. org/10.1037/10594-009

Iqbal, A., 2010, 'Employee turnover: Causes, consequences and retention strategies in the Saudi organizations', The Business Review, Cambridge 16(2), 275-281.

Journal of E-Governance, 2010, 'Global competitiveness index shows Switzerland leading', Journal of E-Governance 33(1), 21-24.

Kanfer, R., Crosby, J.V. \& Brandt, D.M., 1988, 'Investigating behavioral antecedents of turnover at three job years of service levels', Journal of Applied Psychology 73(2), 331-335. http://dx.doi.org/10.1037/0021-9010.73.2.331

Lambert, E., Hogan, N. \& Barton, S., 2001, 'The impact of job satisfaction on turnover intent: A test of a structural measurement model using a national sample of workers', Social Science Journal 38(2), 233-250. http://dx.doi.org/10.1016/S0362 3319(01)00110-0

Ledolter, J. \& Power, M.L., 1984, 'A study of ERISA's impact on private retirement plan growth', Journal of Risk \& Insurance 51(2), 225-243. http://dx.doi. org $/ 10.2307 / 252555$

Lewis, G.B., 1991, 'Turnover and the quiet crisis in the federal civil service', Public Administration Review 51(2), 145-155. http://dx.doi.org/10.2307/977108

Lewis, G.B. \& Frank, S.A., 2002, 'Who wants to work for the government?', Public Administration Review 62(4), 395-404. http://dx.doi.org/10.1111/00333352.00193

Lyness, K.S. \& Judiesch, M.K., 2001, 'Are female managers quitters? The relationships of gender, promotions, and family leaves of absence to voluntary turnover', Journal of Applied Psychology 86(6), 1167-1178. http://dx.doi.org/10.1037/00219010.86.6.1167

Maltarich, M.A., Nyberg, A.J. \& Reilly, G., 2010, 'A conceptual and empirical analysis of the cognitive ability-voluntary turnover relationship', Journal of Applied Psychology 95(6), 1058-1070. http://dx.doi.org/10.1037/a0020331
Mello, J.A., 2011, Strategic human resource management, 3rd edn., South-Western Cengage Learning, $\mathrm{OH}$.

Mobley, W.H., 1982, Employee turnover, causes, consequences, and control, AddisonWesley, Reading, MA.

Mosadeghrad, A.M., Ferlie, E. \& Rosenberg, D., 2008, 'A study of the relationship between job satisfaction, organizational commitment and turnover intention among hospital employees', Health Services Management Research 21, 211-227. http://dx.doi.org/10.1258/hsmr.2007.007015

Mossholder, K.W., Setton, R.P. \& Henagan, S.C., 2005, 'A relational perspective on turnover: Examining structural, attitudinal, and behavioral predictors', Academy of Management Journal 48, 607-618. http://dx.doi.org/10.5465/ AMJ.2005.17843941

Mowday, R.T., Porter, L.W. \& Steers, R.M., 1982, Employee organization linkages: The psychology of commitment, absenteeism, and turnover, Academic Press, New York, NY.

Ng, T.W.H. \& Feldman, D.C., 2009, 'Re-examining the relationship between age and voluntary turnover', Journal of Vocational Behavior 74(3), 283-294. http://dx.doi. org/10.1016/j.jvb.2009.01.004

O'Reilly, C.A. III, Chatman, J. \& Caldwell, D.F., 1991, 'People and organisational culture: A profile comparison approach to assessing person-organisation fit', Academy of Management Journal 34(3), 487-516. http://dx.doi.org/10.2307/256404

Peralta, M.A. \& Stark, A., 2006, 'South Africa: A crossover from inward thinking to a global outlook', Chemical Week 168(35), 41-52.

Pfeffer, J., 2005, 'Changing mental models: HR's most important task', Human Resource Management 44(2), 123-128. http://dx.doi.org/10.1002/hrm.20053

Quinn, A., Rycraft, J.R. \& Schoech, D., 2002, 'Building a model to predict caseworker and supervisor turnover using a neural network and logistic regression', Journa of Technology in Human Services 19(4), 65-85. http://dx.doi.org/10.1300/ J017v19v04_05

Rappaport, A., Bancroft, E. \& Okum, L., 2003, 'The aging workforce raises new talent management issues for employers', Journal of Organisational Excellence 23(1), management issues for employers', Journal

Robison, J., 2010, 'Engagement, wellbeing, and the downturn', Gallup Management Journal Online 1-1. Available from http://www.gallup.com/ businessjournal/125036/despite-downturn-employees-remain-engaged.aspx

Sexton, R.S., McMurtrey, S., Michalopoulos, J.O. \& Smith, A.M., 2005, 'Employee turnover: A neural network solution', Computers \& Operations Research 32(10), 2635-2651. http://dx.doi.org/10.1016/j.cor.2004.06.022

Shamsuzzoha, A.H.M. \& Shumon, M.R.H., 2007, 'Employee turnover - A study of its causes and effects to different industries in Bangladesh', Manufacturing Engineering/Vyrobne Inzinierstvo 6(3), 64-68.

Somers, M.J. \& Birnbaum, D., 1999, 'Survival versus traditional methodologies for studying employee turnover: Differences, divergences and directions for future research', Journal of Organisational Behavior 20(2), 273-284. http://dx.doi. org/10.1002/(SICI)1099-1379(199903)20:2<273::AID-JOB959>3.0.CO;2-X

Sorenson, J.B., 2000, 'The longitudinal effects of group tenure composition on turnover,', American Sociological Review 65(3), 298-310. http://dx.doi. org/10.2307/2657442

Sousa-Poza, A. \& Henneberger, F., 2004, 'Analyzing job mobility with job turnover intentions: An international comparative study', Journal of Economic Issues 38(1), 113-137.

Steel, R.P. \& Ovalle, N.K. II, 1984, 'A review and meta-analysis of research on the relationship between behavioral intentions and employee turnover', Journal of Applied Psychology 69(4), 673-686. http://dx.doi.org/10.1037/0021-9010.69.4.673

Steers, R.M., 1977, 'Antecedents and outcomes of organisational commitment' Administrative Science Quarterly22(1), 46-56. http://dx.doi.org/10.2307/2391745

Sturman, M.C. \& Trevor, C.O., 2001, 'The implications of linking the dynamic performance and turnover literatures', Journal of Applied Psychology 86(4), 684-696. http://dx.doi.org/10.1037/0021-9010.86.4.684

Tett, R.P. \& Meyer, J.P., 1993, 'Job satisfaction, organisational commitment, turnover intention, and turnover: Path analyses based on meta-analytic findings', Personne Psychology 46(2), 259-293. http://dx.doi.org/10.1111/j.1744-6570.1993.tb00874.x

Trevor, C.O., Gerhart, B. \& Boudreau, J.W., 1997, 'Voluntary turnover and job performance: Curvilinearity and the moderating influences of salary growth and promotions', Journal of Applied Psychology 82(1), 44-61. http://dx.doi. org/10.1037/0021-9010.82.1.44

Vance, C.M., Vaiman, V. \& Andersen, T., 2009, 'The vital liaison role of host country nationals in MNC knowledge management', Human Resource Management 48(4), 649-659. http://dx.doi.org/10.1002/hrm.20307

Vandenberg, R.J. \& Nelson, J., 1999, 'Disaggregating the motives underlying turnover intentions: When do intentions predict turnover behavior?', Human Relations (HR) 52(10), 1313-1336. http://dx.doi.org/10.1177/001872679905201005

Wang, X., Wang, H., Zhang, L. \& Cao, X., 2011, 'Constructing a decision support system for management of employee turnover risk', Information Management 12(2), 187-196. http://dx.doi.org/10.1007/s10799-011-0093-6

Westerman, J.W. \& Yamamura, J.H., 2007, 'Generational preferences for work environment fit: Effects on employee outcomes', The Career Development International 12(2), 150-161. http://dx.doi.org/10.1108/13620430710733631

Wocke, A. \& Heymann, M., 2012, 'Impact of demographic variables on voluntary labour turnover in South Africa', International Journal of Human Resource Management 23(16), 3479-3494. http://dx.doi.org/10.1080/09585192.2011.639028 